\title{
Subjective and Objective Evaluation of Total Pelvic Floor Reconstruction with Six-Arm Mesh in Patients with Severe Pelvic Organ Prolapse: A I-Year Retrospective Study
}

This article was published in the following Dove Press journal:

Therapeutics and Clinical Risk Management

Ying Zhao $\mathbb{D}$

Zhi-jun Xia

Qing $\mathrm{Hu}$

Mei-ying Qin

Department of Obstetrics and Gynaecology, Shengjing Hospital of China Medical University, Shenyang, People's Republic of China
Correspondence: Zhi-jun Xia

Department of Obstetrics and Gynecology, Shengjing Hospital of China Medical

University, Shenyang City, Liaoning Province

I 1 0004, People's Republic of China

Tel +86- | 894025I 266

Fax +86-24-83955092

Email xia_pd@163.com
Purpose: To investigate the effect of total pelvic floor reconstruction with a six-arm mesh in the treatment of pelvic organ prolapse.

Patients and Methods: This is a retrospective observational cohort study. A total of 368 patients with pelvic organ prolapse underwent pelvic floor reconstruction surgery. Patients were categorized by the type of surgical mesh: 176 patients received a six-arm mesh and 192 patients received an anteroposterior approach mesh. The 1-year effect of the two groups was compared. The Pelvic Floor Distress Inventory Questionnaire (PFDI-20), Colorectal-Anal Distress Inventory (CRADI-8) and the Pelvic Organ Prolapse Quantitation (POP-Q) staging were used for evaluation. The incidence of complications was recorded. A cure standard was registered by a POP-Q score of grade I or below. A P value $<0.05$ indicates the difference is statistically significant.

Results: There was no recurrence documented in the patients; the cure rate was $100 \%$ in both groups. After surgery, the length of the vagina in the six-arm mesh group was longer than that of the control group at 6 months and 12 months, respectively $(P<0.05)$. The six-arm mesh group had lower PFDI-20 and CRADI- 8 scores after surgery than those of the control group at 6 and 12 months, respectively $(P<0.05)$. Pelvic floor and rectal dysfunction symptom improvement were superior in the six-arm mesh group compared with the control group. After surgery, the Female Sexual Function Inventory (FSFI) score of the six-arm mesh group was superior to that of the control group at 6 and 12 months, respectively $(P<0.05)$. The incidence of complications in the six-arm mesh group was lower than that of the control group $(P<0.05)$.

Conclusion: The total pelvic floor reconstruction using six-arm mesh has the same healing rate as anteroposterior approach mesh surgery, and it is better than traditional surgery in improving subjective symptoms and reducing postoperative complications.

Keywords: pelvic floor reconstruction, pelvic organ prolapse, six-arm mesh

\section{Introduction}

Pelvic organ prolapse (POP) is a common disease of middle-aged and elderly women. The incidence of female POP is approximately $6.8 \%{ }^{1,2}$ The risk of women undergoing surgical treatment for POP is as high as $20 \%,{ }^{3}$ and transvaginal mesh (TVM) implants account for $74.9 \%$ of these operations. ${ }^{4}$

TVM surgery has been widely used for the treatment of POP, but there is a high rate of complications and adverse events, including mesh exposure, postoperative pain, 
difficulty in sexual intercourse, among others. The highest rate of mesh exposure was $16.6 \% .^{5-7}$ Considering the complications of TVM surgery, the US Food and Drug Administration issued two warnings in 2008 and 2011. ${ }^{8}$ As a result, many mesh manufacturers withdrew their products from the market. However, in the past 10 years, the number of TVM procedures has not significantly decreased globally. ${ }^{9-12}$ Although surgeons continue to improve surgical skills, they are also continuously improving the material of the mesh used and the implantation method to try to reduce the incidence of complications after TVM surgery. ${ }^{13}$ TiLOOP ${ }^{\circledR}$ Total six-mesh (pfm medical ag, Cologne, Germany) is made of a lighter titanium polypropylene mesh. The mesh implantation process has also changed. Whether its application can achieve the same therapeutic effect and reduce complications is the key to our research.

\section{Patients and Methods}

This study was designed as a single-center retrospective observational cohort study. Patients with POP who underwent surgical treatment in Shengjing Hospital of China Medical University from January 2016 to December 2018 were evaluated. A total of 396 patients underwent total pelvic floor reconstruction with two different mesh types during this period. We retrospectively analyzed these patients, 368 of whom were followed up for 1 year. The follow-up rate was $92.9 \%$.
Inclusion criteria consisted of all patients with stage III and IV prolapse and anterior, apical, or anterior-combined prolapse types. Patients with posterior POP grade III or IV were excluded. This study was approved by the Ethics Committee of Shengjing Hospital (ethics no.: 2018 PS017J). The enrolled patients were informed of the procedure and they provided written informed consent.

\section{Mesh and Surgical Technique}

All patients underwent total pelvic floor reconstruction with unabsorbable polypropylene (PP) mesh. A total of 192 patients were given the pelvic floor repair mesh Pelvimesh (Herniamesh SRL, Turin, Italy) through an anteroposterior approach to the pelvic floor, and 176 patients were given the six-arm mesh TiLOOP ${ }^{\circledR}$ Total.

Anteroposterior approach mesh is composed of two separate mesh sheets: the anterior pelvic and the posterior pelvic portions. Traditional total pelvic floor reconstruction surgery inserts these two mesh sheets through incisions on the anterior and posterior walls of the vagina. The mesh is placed in the space between the vaginal bladder and the rectovaginal region (Figure 1). The front/middle/rear arms of the mesh sheets pass through the insertion point of the tendinous arch of the pelvic fascia and the sacrospinous ligament (Figure 2). Finally, the arms of mesh sheets are implanted through the skin of the perineum to support the pelvic organs.

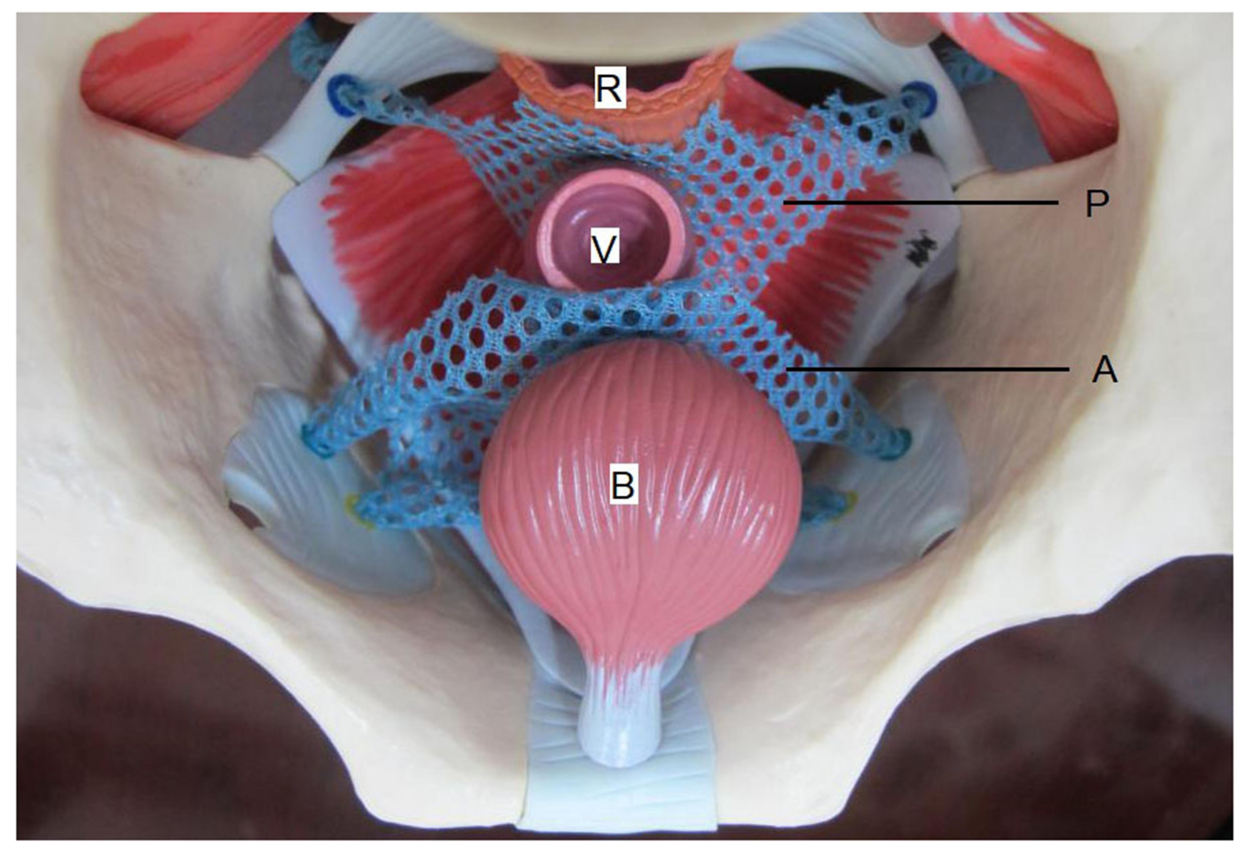

Figure I Schematic diagram of the position of anteroposterior approach mesh.

Notes: A: Mesh in the vaginal bladder space. P: Mesh in the rectovaginal space. B: Bladder. V: Vagina. R: Rectum. 
The six-arm mesh is a one-piece mesh sheet. To insert the six-arm mesh, the surgeon makes only one incision through the anterior wall of the vagina. This mesh sheet is also suspended from the tendinous arch of the pelvic fascia and the sacral ligament. The six-arm mesh is placed in the bladder vaginal space, but unlike anteroposterior approach mesh, it is not located in the rectovaginal space (Figure 3).

\section{Subjective and Objective Evaluation}

At 3, 6, and 12 months after surgery, reexamination was performed by two experienced pelvic floor urologists and the surgeon in an outpatient setting.

The objective evaluation of the patients was performed using the Pelvic Organ Prolapse Quantification (POP-Q) scoring system before and after the surgery. The pelvic landmarks used during the evaluation are as follows: $\mathrm{Ba}$ (point $\mathrm{B}$ anterior) is the most dependent position of the anterior wall, Bp (point $\mathrm{B}$ posterior) is the most dependent position of the posterior wall, and point $\mathrm{C}$ is the cervix or cuff. Points $\mathrm{Ba}, \mathrm{Bp}$, and $\mathrm{C}$ reflect the most serious degree of prolapse of the vaginal walls and uterus. TVL (total vaginal length) reflects the recovery of vaginal length. Recurrence was defined as postoperative POP-Q stage $\geq$ II.
The subjective evaluation of the patients was assessed using the Pelvic Floor Distress Inventory-20 (PFDI-20), including the Pelvic Organ Prolapse Distress Inventory (POPDI-6), the Urogenital Distress Inventory (UDI-6), and the Colorectal-Anal Distress Inventory (CRADI-8) for the statistics of POP, bladder, and rectal symptoms. The score of each part was between 0 and 100, and the total score of all three parts was 300 . Higher scores indicate more severe dysfunction. ${ }^{14,15}$

The improvement of sexual function was evaluated using the Female Sexual Function Index (FSFI) in respect of sexual pain, sexual satisfaction, vaginal lubrication, sexual desire, and sexual arousal. Higher scores indicate better sexual quality. ${ }^{16-18}$ Patients completed paper questionnaires to assess subjective improvement of symptoms at 3,6 , and 12 months after surgery.

\section{Statistical Methods}

SPSS software, version 21.0 was used for data analysis. Continuous variables were expressed as mean and standard deviation (SD), and the comparison between the two groups was analyzed by the paired Student $t$ test or Wilcoxon signed-rank test. Counting data were represented by rate and the difference was tested

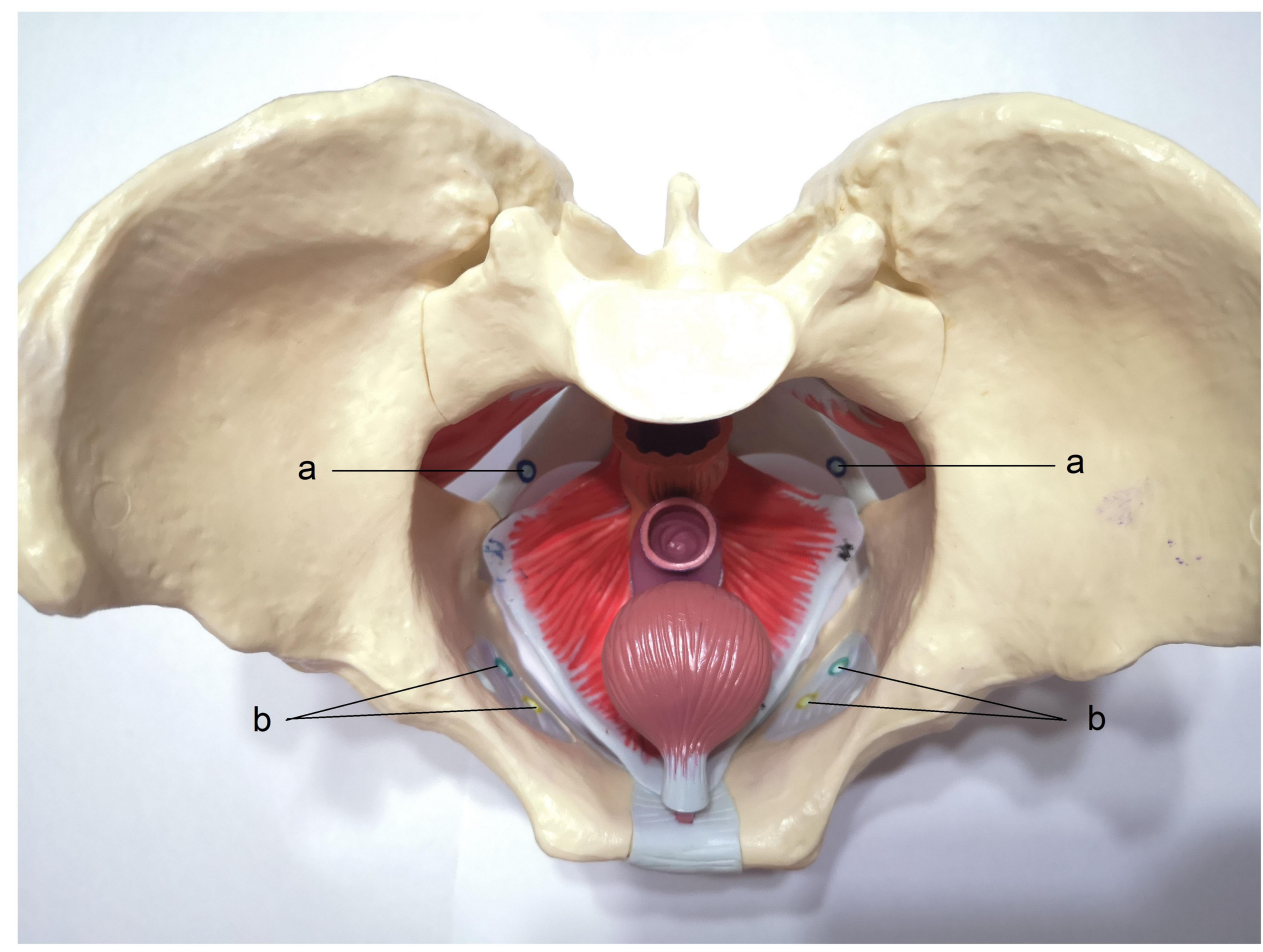

Figure 2 (A) The puncture points of the posterior arm of the mesh in sacrospinous ligament. (B) The puncture points of the anterior and middle arm of the mesh in the obturator. 


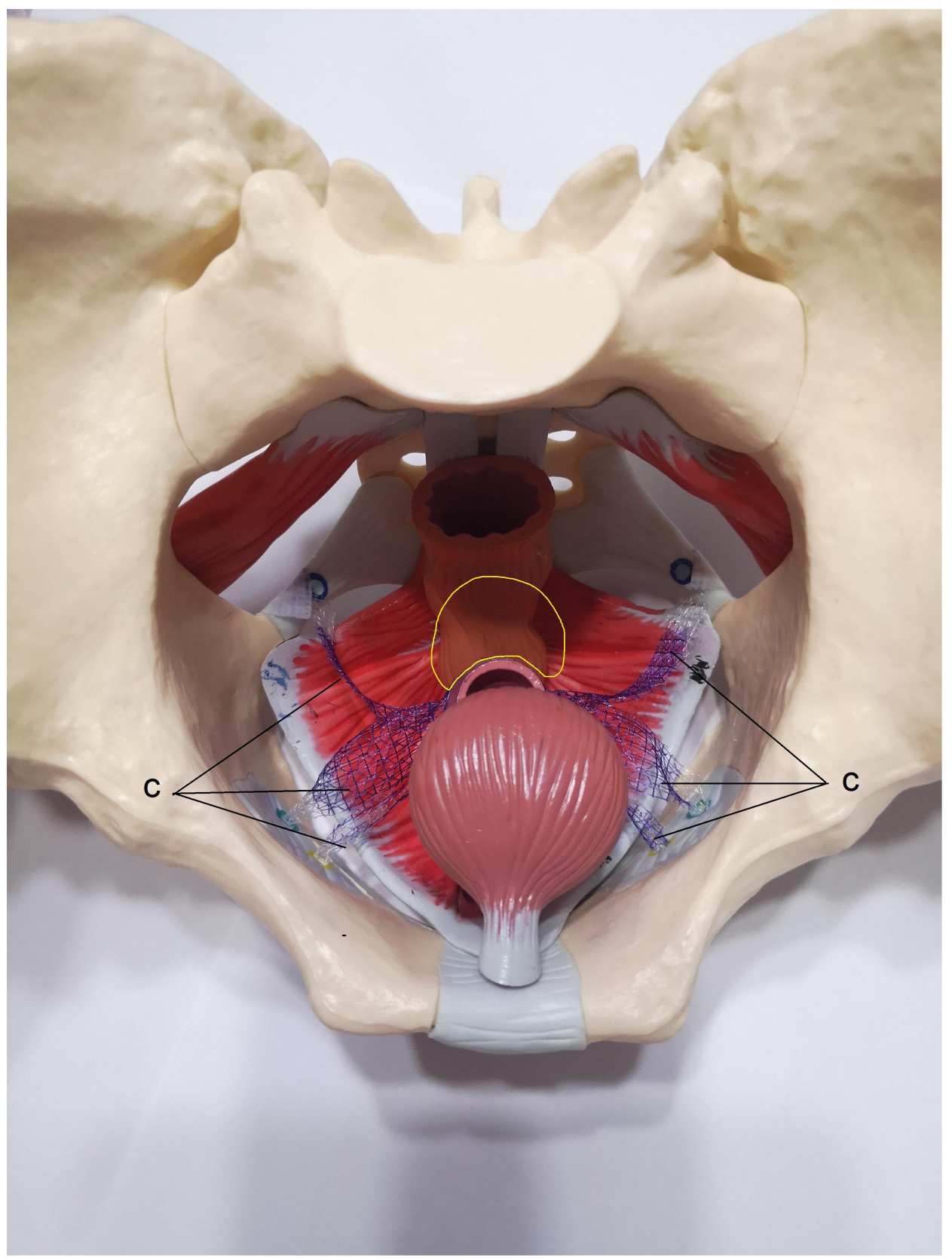

Figure 3 Schematic diagram of the position of six-arm mesh.

Notes: c: The position of the six arms of the mesh. The yellow area: No mesh is inserted in the rectovaginal space.

by chi-square test or Fisher exact test. A $P$ value $<$ 0.05 suggested a statistically significant difference.

\section{Results}

The subjective scores, age, parity, and POP stage had no statistically significant difference between the two groups $(P>0.05)$. There were no cases of posterior vaginal prolapse stage $\geq$ III in both groups (Table 1).
Intraoperative and Postoperative Analysis

All the patients in both groups underwent surgery successfully without injury to the bladder or rectum, and there were no cases of severe bleeding due to vascular injury at the puncture site. During the period of hospitalization after the operation, no severe complications such as delayed bleeding, infection, or abscess formation, occurred. In order to evaluate the surgical and 
Table I Comparison of Patient Clinical Characteristics Between the Two Groups

\begin{tabular}{|c|c|c|c|}
\hline & $\begin{array}{l}\text { Six-Arm } \\
\text { Mesh } \\
\text { Group } \\
(n=I 76)\end{array}$ & $\begin{array}{l}\text { Anteroposterior } \\
\text { Approach Group } \\
(n=192)\end{array}$ & $P$ \\
\hline Age (year) & $66.23 \pm 9.15$ & $67.87 \pm 8.62$ & 0.419 \\
\hline BMI & $26.76 \pm 0.63$ & $26.82 \pm 0.85$ & 0.445 \\
\hline$P$ & $2.51 \pm 1.43$ & $2.32 \pm 1.21$ & 0.168 \\
\hline \multicolumn{4}{|l|}{ Prolapse stage (\%) } \\
\hline III & $96(54.55)$ & $105(54.69)$ & \\
\hline IV & $80(45.45)$ & $87(45.31)$ & \\
\hline \multicolumn{4}{|l|}{ Prolapse position $(\mathrm{N})$} \\
\hline Anterior prolapse & 64 & 71 & \\
\hline Apical prolapse & 24 & 20 & \\
\hline $\begin{array}{l}\text { Anterior and apical } \\
\text { prolapse combined }\end{array}$ & 88 & 101 & \\
\hline Posterior prolapse & - & - & \\
\hline $\begin{array}{l}\text { Instantaneous surgery } \\
\text { for hysterectomy }\end{array}$ & 21 & 23 & \\
\hline $\begin{array}{l}\text { Instantaneous surgery } \\
\text { for urinary } \\
\text { incontinence }(\mathrm{N})\end{array}$ & 26 & 29 & \\
\hline
\end{tabular}

Abbreviations: BMI, body mass index; P, parity.

postoperative conditions in both groups, we compared the intraoperative mesh insertion time, the blood loss volume, the days of indwelling catheter, and the length of hospitalization. The volume of blood loss in the sixarm mesh group was significantly less than that in the anteroposterior approach group $(P<0.05)$. The intraoperative mesh insertion time was significantly shorter in the six-arm mesh group compared with the anteroposterior approach group $(P<0.05)$. There was no significant difference between the two groups in the days of indwelling catheter placement and the length of hospitalization after the surgical procedure $(P>0.05)$ (Table 2$)$.

\section{Comparison of POP-Q Score}

At 1-year follow-up, there were no cases of POP-Q stage $\geq$ II in the two groups, and both groups of patients met the criteria of cure. Furthermore, the indicator points in the POP scoring system were counted and compared before surgery between both groups, and there was no significant difference in AP, BP, C, and TVL between the groups $(P>$ 0.05 ). At 3,6, and 12 months postoperatively, there was no statistically significant difference in $\mathrm{Ba}, \mathrm{Bp}$, and
Table 2 Comparison of Intraoperative Conditions and Postoperative Recovery Between the Two Groups

\begin{tabular}{|l|l|l|l|}
\hline & $\begin{array}{l}\text { Six-Arm } \\
\text { Mesh } \\
\text { Group } \\
\text { (n=176) }\end{array}$ & $\begin{array}{l}\text { Anteroposterior } \\
\text { Approach Group } \\
\text { (n=192) }\end{array}$ & P value \\
\hline $\begin{array}{l}\text { Mesh insertion } \\
\text { time (min) }\end{array}$ & $31.35 \pm 5.14$ & $40.12 \pm 7.35$ & $<0.000 I^{*}$ \\
\hline $\begin{array}{l}\text { Intraoperative } \\
\text { bleeding volume } \\
\text { (mL) }\end{array}$ & $\begin{array}{l}60.26 \\
\pm 15.53\end{array}$ & $65.46 \pm 20.34$ & $<0.000 I^{*}$ \\
\hline $\begin{array}{l}\text { Postoperative } \\
\text { urinary catheter } \\
\text { removal time (d) }\end{array}$ & $3.65 \pm 0.96$ & $3.76 \pm 0.35$ & 0.14 \\
\hline $\begin{array}{l}\text { Residual urine } \\
\text { volume after } \\
\text { urinary extraction } \\
\text { (mL) }\end{array}$ & $\begin{array}{l}57.67 \\
\pm 47.53\end{array}$ & $67.35 \pm 62.46$ & 0.09 \\
\hline $\begin{array}{l}\text { Postoperative } \\
\text { hospital stay (d) }\end{array}$ & $5.43 \pm 1.37$ & $5.54 \pm 1.03$ & 0.38 \\
\hline
\end{tabular}

Notes: The two groups were compared by $t$ test, significance level $\alpha=0.05$. *The difference was statistically significant at a significance level of 0.05 .

C observed between the groups. TVL in both groups increased with surgical repair; however, it was not significantly different at postoperative month 3 , though it was markedly different at postoperative months 6 and 12 (Table 3).

\section{Subjective Symptom Score}

Before surgery, there was no statistical difference in PFDI20 score between the two groups $(P>0.05)$. At 3 months after the operation, the PFDI scores in both groups were lower than before the surgery; however, there was no significant difference in the PFDI scores between both groups at 3 months after the operation $(P>0.05)$. At postoperative months 6 and 12, the PFDI score of the sixarm mesh group was significantly lower than that of the anteroposterior approach group $(P<0.05)$. Further comparisons at 6 and 12 months after surgery showed that there was no significant difference in POPDI-6 and UDI-6 scores between the two groups $(P>0.05)$, whereas the CRADI-8 score of the six-arm mesh group was lower than that of the anteroposterior approach group $(P<0.05)$.

The preoperative FSFI scores of the two groups were not statistically different $(P>0.05)$. Six months after the operation, the FSFI scores of both groups improved. At postoperative months 6 and 12, the FSFI score of the six-arm mesh 
Table 3 Comparison of POP-Q Score in Both Groups Before and at 3, 6, and 12 Months After Surgery

\begin{tabular}{|c|c|c|c|c|}
\hline & & Six-Arm Mesh Group $(n=176)$ & Anteroposterior Approach Group $(n=192)$ & $P$ value \\
\hline \multirow[t]{4}{*}{ Before operation } & $\mathrm{Ba}$ & $+2.21 \pm 0.34$ & $+2.30 \pm 0.53$ & 0.051 \\
\hline & & $+0.54 \pm 0.12$ & $+0.56 \pm 0.15$ & 0.157 \\
\hline & & $-0.22 \pm 0.33$ & $-0.28 \pm 0.42$ & 0.132 \\
\hline & TVL $(\mathrm{cm})$ & $6.65 \pm 1.01$ & $6.44 \pm 1.45$ & 0.106 \\
\hline \multirow[t]{4}{*}{3 months after operation } & $\mathrm{Ba}$ & $-2.57 \pm 0.24$ & $-2.54 \pm 0.40$ & 0.778 \\
\hline & Bp & $-2.74 \pm 0.19$ & $-2.76 \pm 0.22$ & 0.350 \\
\hline & & $-5.46 \pm 0.45$ & $-5.56 \pm 0.56$ & 0.059 \\
\hline & TVL $(\mathrm{cm})$ & $6.63 \pm 0.86$ & $6.68 \pm 0.82$ & 0.569 \\
\hline \multirow[t]{4}{*}{6 months after operation } & $\mathrm{Ba}$ & $-2.54 \pm 0.34$ & $-2.59 \pm 0.33$ & 0.153 \\
\hline & Bp & $-2.68 \pm 0.09$ & $-2.70 \pm 0.18$ & 0.173 \\
\hline & & $-5.85 \pm 0.11$ & $-5.83 \pm 0.52$ & 0.603 \\
\hline & TVL $(\mathrm{cm})$ & $7.45 \pm 0.46$ & $6.83 \pm 0.16$ & $<0.000 \mathrm{I}^{\mathrm{a}}$ \\
\hline \multirow[t]{4}{*}{12 months after operation } & $\mathrm{Ba}$ & $-2.68 \pm 0.21$ & $-2.65 \pm 0.26$ & 0.181 \\
\hline & $\mathrm{Bp}$ & $-2.83 \pm 0.15$ & $-2.8 I \pm 0.14$ & 0.188 \\
\hline & & $-5.64 \pm 0.28$ & $-5.48 \pm 0.56$ & $<0.000 \mathrm{I}^{\mathrm{b}}$ \\
\hline & TVL $(\mathrm{cm})$ & $7.73 \pm 0.58$ & $6.85 \pm 0.23$ & $<0.0001^{\mathrm{a}}$ \\
\hline
\end{tabular}

Notes: $B a$ the most dependent position of the anterior wall, Bp the most dependent position of the posterior wall, $C$ Cervix or cuff, TVL Total Vaginal Length. The two groups were compared by $t$ test, significance level $\alpha<0.05$. ${ }^{a} \mathrm{TVL}$ in two groups was prolonged after surgery, there were significant differences between the two groups at 6 and 12 months after surgery $(P<0.05)$. ${ }^{b}$ There were significant differences in $C$ (cervical position) between the two groups at 12 months after surgery $(P<0.05)$.

group was significantly higher than that of the anteroposterior approach group $(P<0.05)$ (Table 4$)$.

\section{Postoperative Complications}

Complications were evaluated in terms of postoperative recurrence, mesh exposure, vaginal foreign body sensation, dysuria or abnormal defecation, and dyspareunia. The comparison between the two groups is shown in Table 5 .

\section{POP Recurrence}

At 1-year follow-up, there was no recurrence of grade II prolapse or above. The cure rate of both groups was $100 \%$.

\section{Mesh Exposure}

The incidence rate of mesh exposure in the six-arm mesh group and the anteroposterior approach group was $1.70 \%$ and $6.77 \%$, respectively, and there was a statistically significant difference between the two groups $(P=$ 0.02). In the six-arm mesh group, 3 patients were found to have mesh exposure in the vaginal fornix at 6 months after the operation, and there were no cases of mesh exposure at 3 and 12 months. In the anteroposterior approach group, there were 13 patients with mesh exposure ( 4 in the anterior vaginal wall near the vaginal fornix, 4 in the posterior vaginal wall, and 5 in the vaginal fornix). In all cases of mesh exposure, the exposed mesh was 0.3 to $0.8 \mathrm{~cm}$ causing local shearing. After trimming, the tissues exposed to the mesh recovered well, and there was no re-exposure.

\section{Vaginal Foreign Body Sensation}

For patients experiencing vaginal foreign body sensation, we found the cause to be due to the presence of mesh under the vaginal mucosa - not to mesh exposure. There were no cases of vaginal foreign body sensation in the sixarm mesh group. In the anteroposterior approach group, 8 patients presented with symptoms of vaginal foreign body sensation at 6 months postoperatively; the incidence was $4.17 \%$. There was no serious vaginal discomfort in these cases, and after 12 months' follow-up, the symptoms in 4 patients had significantly improved, and the symptoms in the other 4 patients also decreased.

\section{Dysuria or Abnormal Defecation}

After surgery, no patients experienced dysuria or dyschezia in either group, and $6(3.13 \%)$ patients in the anteroposterior approach group experienced mild defecation pain at 6 months, 3 of whom gradually improved and 1 of whom still had the symptom at 12 months. In the sixarm mesh group, there was no discomfort such as pain during defecation after surgery. 
Table 4 Pre- and Postoperative Comparison of PFDI-20 and FSFI Scores Between the Two Groups

\begin{tabular}{|c|c|c|c|c|}
\hline & & Six-Arm Mesh Group $(n=\mid 76)$ & Anteroposterior Approach Group $(n=\mid 92)$ & $P$ value \\
\hline \multirow[t]{5}{*}{ Before operation } & PFDI-20 & $128.32 \pm 37.70$ & $133.5 \pm 42.12$ & 0.216 \\
\hline & POPDI-6 & $64.26 \pm 16.96$ & $66.37 \pm 10.82$ & 0.152 \\
\hline & CRADI-8 & $56.78 \pm 14.79$ & $59.68 \pm 17.88$ & 0.092 \\
\hline & UDI-6 & $36.53 \pm 12.39$ & $38.47 \pm 12.32$ & 0.133 \\
\hline & FSFI & $2.33 \pm 1.5 I$ & $2.57 \pm 1.61$ & 0.142 \\
\hline \multirow[t]{5}{*}{3 months after operation } & PFDI-20 & $26.45 \pm 9.36$ & $27.63 \pm 10.24$ & 0.251 \\
\hline & POPDI-6 & $2.34 \pm 1.93$ & $2.65 \pm 1.64$ & 0.692 \\
\hline & CRADI-8 & $14.36 \pm 5.68$ & $15.36 \pm 5.34$ & 0.082 \\
\hline & UDI-6 & $14.65 \pm 3.62$ & $15.14 \pm 3.44$ & 0.184 \\
\hline & FSFI & - & - & - \\
\hline \multirow[t]{5}{*}{6 months after operation } & PFDI-20 & $23.78 \pm 5.25$ & $28.26 \pm 5.97$ & $<0.000 \mathrm{I}^{\mathrm{a}}$ \\
\hline & POPDI-6 & $2.38 \pm 1.4 \mathrm{I}$ & $2.53 \pm 1.05$ & 0.245 \\
\hline & CRADI-8 & $7.46 \pm 3.01$ & $12.17 \pm 5.02$ & $<0.000 \mathrm{I}^{\mathrm{b}}$ \\
\hline & UDI-6 & $11.06 \pm 3.32$ & $11.73 \pm 3.82$ & 0.075 \\
\hline & FSFI & $24.03 \pm 7.66$ & $20.23 \pm 5.31$ & $<0.0001^{\mathrm{c}}$ \\
\hline \multirow[t]{5}{*}{12 months after operation } & PFDI-20 & $16.23 \pm 5.12$ & $21.86 \pm 5.28$ & $<0.000 \mathrm{I}^{\mathrm{a}}$ \\
\hline & POPDI-6 & $1.35 \pm 1.21$ & $1.28 \pm 1.14$ & 0.568 \\
\hline & CRADI-8 & $5.52 \pm 1.87$ & $8.89 \pm 1.65$ & $<0.000 \mathrm{I}^{\mathrm{b}}$ \\
\hline & UDI-6 & $8.96 \pm 2.03$ & $9.28 \pm 2.16$ & 0.145 \\
\hline & FSFI & $35.63 \pm 13.64$ & $23.76 \pm 8.48$ & $<0.0001^{c}$ \\
\hline
\end{tabular}

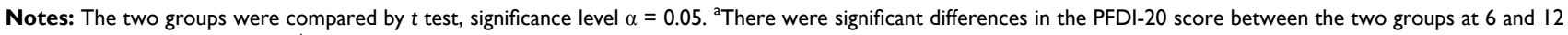
months after surgery $(P<0.05)$. ${ }^{\mathrm{b}}$ There were significant differences in the CRADI-8 score between the two groups at 6 and 12 months after surgery $(P<0.05)$. ${ }^{\mathrm{C}}$ There were significant differences in the FSFI score between the two groups at 6 and 12 months after surgery $(P<0.05)$.

Table 5 Comparison of Postoperative Complications Between the Two Groups

\begin{tabular}{|l|l|l|l|}
\hline & Six-Arm Mesh Group (n= 176) & Anteroposterior Approach Group (n=1 92) & $P$ \\
\hline POP recurrence & 0 & 0 & - \\
Mesh exposure & $3(1.70 \%)$ & $13(6.77 \%)$ & 0.02 \\
Vaginal foreign body sensation & 0 & $8(4.17 \%)$ & 0.008 \\
Defecation pain & 0 & $6(3.13 \%)$ & 0.031 \\
Dysuria or dyschezia & 0 & 0 & - \\
Dyspareunia & $1 / 98(1.02 \%)$ & $15 / 103(14.56 \%)$ & $<0.001$ \\
\hline
\end{tabular}

\section{Dyspareunia}

In the six-arm mesh group, 98 patients who had resumed sexual function felt that their preoperative sexual discomfort had improved after surgery. One patient had mild pain and discomfort during sexual intercourse at postoperative month 6 , but it resolved by postoperative month 12 . In the anteroposterior approach group, 103 patients resumed sexual function after surgery. Fifteen patients felt mild pain or discomfort during sexual intercourse at 6 months after the surgery, of whom 5 patients improved and 10 patients still experienced symptoms at 12 months. The incidence of dyspareunia in the six-arm mesh group was lower than that of the anteroposterior approach group, and there was a statistically significant difference in the incidence rate of dyspareunia between the two groups.

\section{Discussion}

Total pelvic floor reconstruction surgery is widely used in the treatment of POP. Because this surgery involves the implantation of foreign material, we are not only concerned about surgically treating the prolapse but also both the surgical and clinical complications caused by mesh insertion. ${ }^{19}$ Therefore, our research focuses on making continuous improvements to pelvic floor reconstruction surgery in order to reduce the incidence of surgical complications while ensuring surgical efficacy. Through the diagnosis, treatment, and research of 
a large number of patients with POP, we found that most patients with prolapse have mainly anterior and apical prolapse, and fewer patients have posterior prolapse. Many cases of posterior prolapse are caused by prolapse of the apical part of the vagina, rather than by rectocele. For such cases without substantial rectocele, the application of six-arm mesh surgery can not only ensure surgical success but also improve subjective symptoms and reduce the incidence of mesh complications.

Six-arm pelvic floor reconstruction surgery and traditional surgery have the same pelvic floor organ suspension theory, and the positions of the mesh suspension are also the same. They are reconstruction procedures for anterior and apical POP without rectal prolapse. ${ }^{20}$ Follow-up at 1-year showed that this procedure had a surgical effect similar to traditional pelvic floor reconstruction procedures in anatomical reduction; there were no cases of POP (grade II and above) recurrence, and the objective cure rate was up to $100 \%$. At 12 months after surgery, TVL in the observation group was longer than that in the control group, indicating that the six-arm mesh procedure is superior to traditional mesh procedures in postoperative vaginal extensibility.

Recurrence of vaginal vault prolapse is not uncommon; although there are many surgical methods to treat POP, there is still controversy about the best treatment for recurrence of vaginal vault prolapse. Vitale et $\mathrm{al}^{21}$ reported that transvaginal bilateral sacrospinous fixation has a cure rate of $80 \%$ for recurrences of vaginal vault prolapse. Coolen et $\mathrm{al}^{22}$ found that vaginal mesh has a high cure rate for second recurrences of vaginal vault prolapse, but mesh exposure was seen most often after vaginal mesh. Six-arm mesh surgery primarily provides fixation of the apical and anterior pelvic cavity. The short-term results for initial treatment of apical prolapse have been demonstrated in our research. If it is applied to recurrent vaginal vault prolapse, the risk of mesh exposure will be reduced, but we advise further clinical trials for verification.

Although there is a positive cure rate for these two kinds of surgery, we are concerned with improving the patients' postoperative symptoms and complications. There are several research reports documenting the postoperative complications of pelvic floor reconstruction surgery. ${ }^{23,24}$ The ultimate aim of these reports is to find better surgical techniques and methods to reduce postoperative complications. This is also the main purpose of our research.

The six-arm mesh is completely inserted into the pelvic floor space through the anterior vagina; there is no mesh in the space between the posterior vagina and the rectum, which reduces patient discomfort. The improvement in subjective symptoms was mainly noted in the rectal area. The six-arm mesh was superior to the anteroposterior approach mesh in the improvement of defecation difficulty and pain. Mesh exposure is a common and significant complication of pelvic floor reconstruction. In this study, the incidence rate of mesh exposure after total pelvic floor reconstruction with six-arm mesh was significantly lower than that after traditional procedures. This is because only one entry incision is made in the anterior wall of the vagina during the six-arm mesh procedure versus two entry incisions made in the anterior and posterior vaginal walls during anteroposterior approach surgery.

Pelvic organ prolapse is a very common condition in the female population with a severe impact on quality of life and a significant impairment of sexual function. The quality of sex life was emphasized by most patients. ${ }^{23}$ Six-arm mesh surgery also benefits patients by improving sexual function. Geller et $\mathrm{al}^{24}$ monitored 160 patients with mesh insertion for 20 months and found that, after surgery, the incidence rates of pelvic pain and dyspareunia were $15.6 \%$ and $19 \%$, respectively. As reported in the literature, the incidence rate of discomfort during sexual intercourse after pelvic floor reconstruction is $4 \%$ to $20 \%^{20-26}$ by 5-year long-term followup; Meyer et $\mathrm{al}^{27}$ found the rate to be as high as $36 \%$. In our research, the incidence of dyspareunia in the six-arm mesh group was $1.02 \%$, which was significantly lower than that in the traditional group $(14.56 \% ; P<0.001)$. The improvement in FSFI scores was also more pronounced in six-arm mesh surgery compared with conventional surgery. Six-arm mesh surgery had a lower incidence of sexual dysfunction and a significant improvement in sexual function compared with traditional surgery; this is another important advantage of sixarm mesh surgery.

POP has a high incidence in women. As a type of functional disorder, it seriously affects the quality of life of patients, and the symptoms involve the expertise of specialists from multiple disciplines including urology, proctology, gynecology, and sexology. When we diagnose and treat these diseases, we should not only consider the restoration of organ position but also pay attention to the restoration of function. The assessment and management of a multidisciplinary approach are very important. The effect on patients is not only physical but also psychological. ${ }^{28}$ We need to identify the symptoms of pelvic floor dysfunction more carefully through questionnaires and other methods, such as health-related quality of life (HRQoL) as estimated by 15D-index measures (discomfort profile, sexual activity, distress, and mobility), PFDI-20, FSFI, and others. $^{29}$ Only by evaluating each subjective symptom 
accurately can we improve the technique of pelvic floor reconstruction and treat POP with more effective methods.

A limitation of this study is the limited follow-up period and use of a single research institution. In the future, we hope to ascertain the long-term effect of sixarm mesh reconstruction through multicenter research. As a retrospective study, it is inevitable that a small number of cases were lost to follow-up; this will have some effect on the results of the study. We also look forward to further prospective studies in the future.

\section{Conclusion}

In conclusion, total pelvic floor reconstruction with sixarm mesh has resulted in patient satisfaction with improvement in pain or discomfort with defecation and sexual activity as evidenced by higher patient scores on subjective questionnaires. Therefore, this new procedure is an ideal choice for the treatment of severe POP, particularly anterior and apical POP.

\section{Ethics Approval and Informed Consent}

All procedures performed in studies involving human participants were in accordance with the ethical standards of the institutional and national research committee (Ethics Committee of Shengjing Hospital, 2018PS017J) and with the 1964 Helsinki Declaration and its later amendments or comparable ethical standards. All patients were provided with informed consent and willing to participate in this study.

\section{Acknowledgments}

The authors gratefully acknowledge the assistance of Science and Technology Plan of Shenyang, China, for supporting this work. We also thank the patients of the Pelvic Floor Diagnosis and Treatment Center of Shengjing Hospital for their help with this research.

\section{Funding}

There is no funding to report.

\section{Disclosure}

The authors report no conflicts of interest in this work.

\section{References}

1. Zeleke BM, Bell RJ, Billah B, Davis SR. Symptomatic pelvic floor disorders in community-dwelling older Australian women. Maturitas. 2016;85:34-41. doi:10.1016/j.maturitas.2015.12.012
2. Masenga GG, Shayo BC, Rasch V. Prevalence and risk factors for pelvic organ prolapse in Kilimanjaro, Tanzania: a population based study in Tanzanian rural community. PLoS One. 2018;13:e0195910. doi:10.1371/journal.pone. 0195910

3. Smith FJ, Holman CD, Moorin RE, Tsokos N. Lifetime risk of undergoing surgery for pelvic organ prolapse. Obstet Gynecol. 2010;116:1096-1100. doi:10.1097/AOG.0b013e3181f73729

4. Jonsson Funk M, Edenfield AL, Pate V, Visco AG, Weidner AC, Wu JM. Trends in use of surgical mesh for pelvic organ prolapse. Am J Obstet Gynecol. 2013;208:71-79. doi:10.1016/j. ajog.2012.11.008

5. Ubertazzi EP, Soderini HFE, Saavedra Sanchez AJM, Fonseca Guzman C, Paván LI. Long-term outcomes of transvaginal mesh (TVM) in patients with pelvic organ prolapse: a 5-year follow-up. Eur J Obstet Gynecol Reprod Biol. 2018;225:90-94. doi:10.1016/j. ejogrb.2018.03.060

6. Duport C, Duperron C, Delorme E. Anterior and middle pelvic organ prolapse repair using a six tension-free strap low weight transvaginal mesh: long-term retrospective monocentric study of 311 patients. J Gynecol Obstet Hum Reprod. 2019;48:143-149. doi:10.1016/j. jogoh.2018.11.008

7. Withagen MI, Vierhout ME, Hendriks JC, Kluivers KB, Milani AL. Risk factors for exposure, pain, and dyspareunia after tension-free vaginal mesh procedure. Obstet Gynecol. 2011;118:629-636. doi:10.1097/AOG.0b013e31822ada95

8. US Department of Health and Human Services; Food and Drug Administration Center for Devices and Radiological Health UPDATE on Serious Complications Associated with Transvaginal Placement of Surgical Mesh for Pelvic Organ Prolapse. FDA safety communication; 2011. Available from: http://2015.iuga.org/wpcontent/uploads/workshops/ws29_literature7.pdflast. Accessed August 21, 2019.

9. Withagen MI, Vierhout ME, Hendriks JC, Kluivers KB, Milani AL. Quality of life in women of non-reproductive age with transvaginal mesh repair for pelvic organ prolapse: A cohort study. Int $J$ Surg. 2016;33:36-41. doi:10.1016/j.ijsu.2016.07.062

10. Wan OY, Chan SS, Cheung RY, Chung TK. Mesh- related complica tions from reconstructive surgery for pelvic organ prolapse in Chinese patients in Hong Kong. Hong Kong Med. 2018;24:369-377.

11. Allègre $\mathrm{L}$, Callewaert $\mathrm{G}$, Alonso $\mathrm{S}$, et al. Long-term outcomes of a randomized controlled trial comparing trans-obturator vaginal mesh with native tissue repair in the treatment of anterior vaginal wall prolapse. Int Urogynecol J. 2019;31:745-753. doi:10.1007/s00192-01904073-x

12. Lo TS, Tan YL, Cortes EF, Wu PY, Pue LB, Al-Kharabsheh A. Clinical outcomes of mesh exposure/extrusion: presentation, timing and Management. Aust N Z J Obstet Gynaecol. 2015;55:284-290. doi:10.1111/ajo.12340

13. Guyomard A, Delorme E. Transvaginal treatment of anterior or central urogenital prolapse using six tension-free straps and light mesh. Int J Gynaecol Obstet. 2016;133:365-369. doi:10.1016/j. ijgo.2015.10.016

14. Ma Y, Xu T, Zhang Y, Mao M, Kang J, Zhu L. Validation of the chinese version of the pelvic floor distress inventory-20 (PFDIi-20) according to the cosmin checklist. Int Urogynecol $J$. 2019;30:1127-1139. doi:10.1007/s00192-018-3847-4

15. Barber MD, Walters MD, Bump RC. Short forms of two condition-specific quality-of -life questionnaires for women with pelvic floor disorders (PFDI-20 and PFIQ-7). Am J Obstet Gynecol. 2005;193:103-113. doi:10.1016/j.ajog.2004.12.025

16. Witting K, Santtila P, Jern P, et al. Evaluation of the female sexual function index in a population based sample from Finland. Arch Sex Behav. 2008;37(6):912-924. doi:10.1007/ s10508-007-9287-8 
17. Rogers RG, Pauls RN, Thakar R, et al. An international Urogynecological association (IUGA)/international continence society (ICS) joint report on the terminology for the assessment of sexual health of women with pelvic floor dysfunction. Int Urogynecol J. 2018;29:647-666. doi:10.1007/s00192-018-3603-9

18. Neijenhuijs KI, Hooghiemstra N, Holtmaat K, et al. The female sexual function index (FSFI)-A systematic review of measurement properties. $J$ Sex Med. 2019;16:640-660. doi:10.1016/j.jsxm.2019.03.001

19. Khan ZA, Thomas L, Emery SJ. Outcomes and complications of trans-vaginal mesh repair using the Prolift kit for pelvic organ prolapse at 4 years median follow-up in a tertiary referral centre. Arch Gynecol Obstet. 2014;290:1151-1157. doi:10.1007/s00404-014-3316-3

20. Laso-García IM, Rodríguez-Cabello MA, Jiménez-Cidre MA, et al. Prospective long-term results, complications and risk factors in pelvic organ prolapse treatment with vaginal mesh. Eur J Obstet Gynecol Reprod Biol. 2017;211:62-67.22. doi:10.1016/j.ejogrb.2017.02.005

21. Vitale SG, Laganà AS, Noventa $M$, et al. Transvaginal bilateral sacrospinous fixation after second recurrence of vaginal vault prolapse: efficacy and impact on quality of life and sexuality. Biomed Res Int. 2018;2018:5727165. doi:10.1155/2018/5727165

22. Coolen AWM, Bui BN, Dietz V, et al. The treatment of post-hysterectomy vaginal vault prolapse: a systematic review and meta-analysis. Int Urogynecol J. 2017;28(12):1767-1783. doi:10.1007/s00192-017-3493-2

23. Kinjo M, Yoshimura Y, Kitagawa Y, Okegawa T, Nutahara K. Sexual activity and quality of life in Japanese pelvic organ prolapse patients after transvaginal mesh surgery. J Obstet Gynaecol Res. 2018;44 (7):1302-1307. doi:10.1111/jog.13654
24. Geller EJ, Babb E, Nackley AG, Zolnoun D. Incidence and risk factors for pelvic pain after mesh implant surgery for the treatment of pelvic floor disorders. J Minim Invasive Gynecol. 2017;24:67-73. doi:10.1016/j.jmig.2016.10.001

25. Alperin M, Ellison R, Meyn L, Frankman E, Zyczynski HM. Twoyear outcomes after vaginalprolapse reconstruction with mesh pelvic floor repair system. Female Pelvic MedReconstr Surg. 2013;19 (2):72-78. doi:10.1097/SPV.0b013e3182841d4b

26. Abed H, Rahn DD, Lowenstein L, et al. Incidence and management of graft erosion wound granulation, and dyspareunia following vaginal prolapse repair with graft materials: a systematic review. Int Urogynecol J. 2011;22:789-798. doi:10.1007/s00192-011-1384-5

27. Meyer I, McGwin G, Swain TA, Alvarez MD, Ellington DR, Richter HE. Synthetic graft augmentation in vaginal prolapse surgery: long-term objective and subjective outcomes. Minim Invasive Gynecol. 2016;23:614-621. doi:10.1016/j.jmig.2016.02.014

28. Laganà AS, La Rosa VL, Rapisarda AMC, Vitale SG. Pelvic organ prolapse: the impact on quality of life and psychological well-being. J Psychosom Obstet Gynaecol. 2018;39(2):164-166. doi:10.1080/ 0167482X.2017.1294155

29. Altman D, Geale K, Falconer C, Morcos E. A generic health-related quality of life instrument for assessing pelvic organ prolapse surgery: correlation with condition-specific outcome measures. Int Urogynecol J. 2018;29(8):1093-1099. doi:10.1007/s00192-018-3587-5
Therapeutics and Clinical Risk Management

\section{Publish your work in this journal}

Therapeutics and Clinical Risk Management is an international, peerreviewed journal of clinical therapeutics and risk management, focusing on concise rapid reporting of clinical studies in all therapeutic areas, outcomes, safety, and programs for the effective, safe, and sustained use of medicines. This journal is indexed on PubMed Central, CAS,

\section{Dovepress}

EMBase, Scopus and the Elsevier Bibliographic databases. The manuscript management system is completely online and includes a very quick and fair peer-review system, which is all easy to use. Visit http://www.dovepress.com/testimonials.php to read real quotes from published authors. 